\title{
Cultura Literária Contemporânea no Brasil: Notas Sobre Internet, Poesia e Resistência.
}

Sandro Ornellas ${ }^{1}$

Diante da tradição do saber aristocrático da cultura ocidental, a rede democratiza saberes, porém, por meio de protocolos e confianças, aristocratiza interfaces de programas.

Edson Passetti, Anarquismos e sociedade de controle (2003: 31)

\section{Articulações complexas}

Iniciando a reflexão por um gracejo, diríamos que Gilles Deleuze e Félix Guattari fizeram um pouco da sua fama com o uso - dentre outras ferramentas conceituais por eles criadas e que se tornaram verdadeiros clichês da teoria crítica contemporânea - do rizomático "e... e... e..." (Deleuze/Guattari, 1995: 37). Virou uma espécie de fetiche metodológico interdisciplinar querer dar conta das complexas mutações culturais do nosso tempo com a relação entre campos diversos através do uso do "e... e... e...", articulando muitas vezes campos até aproximadamente sessenta anos atrás entendidos como autônomos, quando não inexistentes. Ao mesmo tempo, é de fato muito produtivo como campos aparentemente ultrapassados retornam com grande força teórica nessas novas articulações.

\footnotetext{
${ }^{1}$ Doutor em Letras e Linguística (Teorias e crítica da cultura e da literatura) pela Universidade Federal da Bahia UFBA. Professor do Departamento de Letras Vernáculas do Instituto de Letras e do Programa de Pós-Graduação em Literatura e Cultura da Universidade Federal da Bahia.
}

Brasiliana - Journal for Brazilian Studies. Vol. 3, n.1 (Jul. 2014). ISSN 2245-4373. 
Tomemos as Humanidades como grande área de estudos voltados para a lógica da cultura humana e seus diversos produtos, organizações e manifestações. Uma teorização recente que tenta dar conta e projetar possíveis bases para esse retorno das Humanidades foi elaborada pelo crítico alemão Hans Ulrich Gumbrecht no seu livro Produção de presença, publicado originalmente em 2004. No quinto capítulo, Gumbrecht faz profissão de fé de um novo sentido para as Humanidades, baseado em três eixos de práticas críticas: a história, a estética e o ensino. Com a história, fala Gumbrecht das “técnicas que produzem a sensação (ou melhor, a ilusão) de que os mundos passados podem tornar-se de novo tangíveis" (2010: 123) - o que podemos articular com a grande importância que a noção de memória histórica possui na reflexão contemporânea. Por estética, Gumbrecht frisa "a relevância epistemológica particular inerente ao tipo de epifania que [a estética] pode suscitar" (2010: 122). Quanto ao ensino, afirma ele estar convencido de que "a tarefa mais importante que temos hoje é confrontar os alunos com a complexidade intelectual, o que significa que devemos concentrar nossa atenção nos gestos dêiticos, apontando a condensação ocasional dessa complexidade" (2010: 123). Resume, então, Gumbrecht: presentificação, epifania e dêixis seriam as categorias fundamentais de sua proposta de Humanidades para um futuro próximo.

É, portanto, justamente diante dessas três categorias propostas pelo crítico alemão que iniciamos nosso texto sobre algumas das produtivas relações que vem se estabelecendo no século XXI entre a rede mundial de computadores, conhecida como internet, a facilitação do acesso às novas tecnologias $e$ (como diriam Deleuze e Guattari) a vida literária contemporânea. Nosso texto fará as vezes de uma espécie de estudo de caso exemplar de algumas das complexidades do mundo contemporâneo. Exemplar porque a relação da literatura - particularmente do que ainda podemos chamar, a partir de um certo senso comum, de texto poético, ou mesmo poesia - com a internet parece comportar, de certa maneira, essas categorias propostas por Gumbrecht. 
Em primeiro lugar, pelo ensino, é cada dia mais evidente que a internet pode e deve contribuir para a escola e a educação, justamente pelo acesso rápido e fácil a uma pedagógica intersemiose de fontes para os "gestos dêiticos" que tentam demonstrar a complexidade crescente da nossa vida. Em segundo lugar, pela história, a disponibilização dessas fontes na internet parece torná-la um imenso arquivo público em que o passado se torna tangível como memória permanente e presentificável num simples apertar de botões, condensando exponencialmente tempo e espaço e possibilitando novas experiências e percepções. Em terceiro lugar, pela estética, depois de proclamado de diversas formas e em diversas épocas o desinteresse pela leitura literária e a morte da poesia, eis que a internet propicia o retorno com força de uma nova geração de escritores, poetas e leitores para as "epifanias" e debates literário-culturais no Brasil. Mostra-se assim que a poesia ainda pode seduzir leitores, como comprovam o exemplo de Fabrício Carpinejar, cujo inteligente uso de redes sociais o ajuda a se divulgar e vender seus livros de poemas, alguns em terceira edição, ou o exemplo do sucesso de vendas da Poesia Completa de Paulo Leminski, lançada em 2013 - nos levando a concluir, a contrapelo do lugar-comum sempre reafirmado pelos editores, que poesia pode vender, sim.

Quem hoje ainda for capaz de navegar de forma curiosa e livre pelas vias do mundo virtual, com olhos particularmente interessados em literatura brasileira, já percebeu que a vida literária - que nos séculos XIX e XX se alimentava de grupos, debates, polêmicas, críticas escritas, interesses, fofocas e textos no circuito que era formado pelos salões, jornais, revistas, cafés, escolas e casas editoriais, conforme Pierre Bourdieu apontou de modo categórico (1992) - migrou de rápida e intensamente para a internet. Na sua feição de vida total, na qual temos a sobreposição de espaços antes disciplinarmente separados, tais como escola, trabalho, casa, rua, loja, bar, livraria, biblioteca, editora, etc. a internet é capaz de comportar diferentes grupos e perfis de 
interessados em poesia, fazendo-a voltar a ocupar um lugar relevante no mundo literário. São blogs de poetas, de jornalistas literários, de editores, de escritores, de leitores, de professores e de pesquisadores tratando de absolutamente todos os assuntos relativos ao campo literário e mesclando seus diversos pontos de vista numa babel virtual. Além disso, há revistas literárias de vários tipos, das mais amadoras às mais profissionais ou academicamente especializadas, múltiplos sites e redes sociais, dos mais simples aos mais experimentais, cometendo o feito de conseguir - como se fosse uma grande e permanente feira literária - com que todos se encontrem, se correspondam, se leiam e se comentem. E muitas vezes discutam - calorosamente. Antes da internet, portanto, o campo literário parecia destinado à marginalidade e estigmatização econômica e social, pois a sua constituição no século XIX, forjada com a ideia de uma autonomia estética, levou sobretudo poetas, mas não apenas eles, a acreditar na autossuficiência do seu discurso em relação aos valores e instituições sociais e mercadológicos.

Hoje o campo literário se transforma com as mutações tecnoculturais. Não que se tenha abandonado completamente a ideia de autonomia estética e literária. Mas se podemos dizer que a internet é o que melhor representa a hipercomplexidade presente na cultura contemporânea, isso pode ser observado também facilmente no próprio modo como a produção literária nela se reconfigura. De um lado, são inúmeros os artistas que já entenderam essa lógica hipercomplexa e começam a construir obras fortissimamente amalgamadas a ela, fundindo formas de criação artística às novas tecnologias da informação e confundindo habilidosamente produção artística, divulgação mercadológica e marketing pessoal, tudo interconectado com possíveis leitores pela internet enquanto gigantesca plataforma onde todos potencialmente se encontram. Ela os ajuda a disponibilizar seus produtos de forma ampla e menos atravessados pelos seus tradicionais intermediários: críticos, jornalistas, professores e 
editores. De outro lado, também, ao longo da última década, percebe-se um forte retorno dos grandes clássicos escolares, em que obras de domínio público como as de Machado de Assis e Fernando Pessoa, para falar de autores de língua portuguesa, são usadas para as mais diversas finalidades: desde trabalhos acadêmicos, mesmo de scholars, até juvenis postagens sentimentais em blogs e redes sociais ou como simples forma de cultivo literário. Essas obras muitas vezes acabam alimentando um interesse renovado pela tradicional cultura letrada, mas que às vezes vem acompanhado de discursos também tradicionais, quando não fortemente conservadores, do ponto de vista sociopolítico, fazendo discussões sobre estilos e biografias atravessarem violentamente os debates.

\section{Contaminações poéticas}

Arriscamos afirmar que os poetas parecem ser os que mais ganharam com a paulatina virtualização do campo literário. Poderíamos mesmo dizer que foi a poesia, mas há uma espécie de "competição" desleal nas infovias entre autores contemporâneos e canonizados. Estes são infinitamente mais citados, lidos e compartilhados nas redes do que os vivos. Dois exemplos devidamente conhecidos são no que transformaram versos e frases de Fernando Pessoa e Ana Cristina César, muitas vezes a eles sendo dada a autoria de textos apócrifos. Juntemos a isso que recentemente o poeta-performer Ricardo Aleixo criticou uma premiação de Ferreira Gullar, considerando-a uma espécie de gesto redundante, assim como uma incapacidade de se ver a efervescente produção contemporânea brasileira. Mas se os poetas canonizados (ou em vias de canonização, como no caso de Gullar) são mais visíveis, o que parece absolutamente compreensível, os emergentes encontraram na internet um campo de possibilidades infinitamente 
enriquecedor, tanto do que respeita à produção literária quanto à circulação e divulgação.

É o que se percebe no caso do poeta Ricardo Domeneck. Mix de poeta, artista audiovisual, performer, tradutor, crítico literário e DJ, morador de Berlim há mais de dez anos, Domeneck se tornou uma figura muito presente no meio literário brasileiro do século XXI, publicando, acompanhando e intervindo criticamente nele, justamente com a ajuda da internet. Ele é um típico exemplar da mutante confluência entre a tradição literária moderna e a novas tecnologias da comunicação e informação. E sabe se valer muito bem disso, pois mesmo morando longe do Brasil e circulando por festivais de poesia europeus, não perde a oportunidade de estar virtualmente presente nas movimentações do campo nacional, opinando e publicando. Uma visita ao blog de Domeneck, o Rocirda Demencock, assim como a abertura de algum dos seus cinco livros de poemas, revelará um autor filiado de certa maneira à grande tradição de impessoalidade da poesia moderna, um tanto próximo à linhagem Mallarmé-RilkeStein, como se pode perceber: “o acaso que nos / ocupa produz-se / quando a memória / esvazia-se não / quando a memória / trabalha" (2007: 67). Mas, ao mesmo tempo, há em sua poesia um certo retorno - bem contemporâneo - à presença de um sujeito, através de modos de subjetivação homoafetiva (entre outras) que resultam numa poesia que poderíamos chamar de pós-vanguardista, na falta de melhor definição, e que percebemos na releitura - agora completa - do mesmo poema anterior:

o acaso que nos

ocupa produz-se

quando a memória

esvazia-se não

quando a memória

trabalha

as erupções da pele sã- 


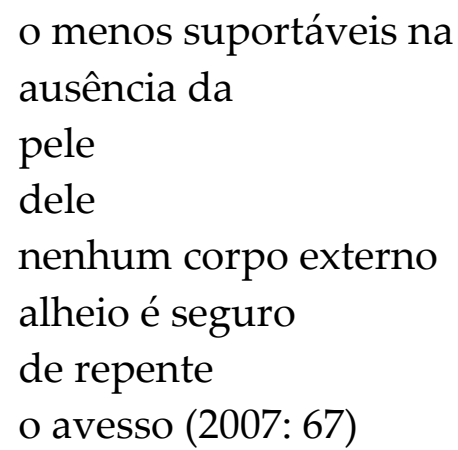

Essa confluência percebida - entre a tradição literária moderna de uma impessoalidade textual e os modos de subjetivação discursiva ("pele / dele") que têm sido turbinados no Brasil pelo ambiente das novas tecnologias da comunicação e informação (e aqui apenas sugiro a possibilidade de se avançar na leitura do poema a partir da rima destacada entre o substantivo "pele" e o pronome "dele" em suas implicações relativas ao complexo sexo-gênero, sobretudo se pensarmos num discurso homoerótico e em suas especificidades nas sociedades contemporâneas) - se torna mais clara em Domeneck através da performance audiovisual "Garganta com texto", na qual o jovem poeta aparece de peito para cima, deitado numa banheira, enquanto fala um texto de inflexão nitidamente ensaística, com dicção bem calculada e olhando para a câmera colocada acima dele, em ângulo de noventa graus. Nesse texto, ele a certa altura diz: "poesia não é literatura, poesia é uma performance, levada a cabo por homens e mulheres de carne e osso, com uma biografia específica, com uma educação específica, que eles não têm como simplesmente ignorar (...)" (Domeneck, 2006). Esse texto é ritmicamente falado, à medida que a banheira pouco a pouco se enche de água, até o ponto de cobrir totalmente seu corpo e seu rosto, calando-o. Aí, a intersemiose produtivamente casa a tradição moderna da poesia como exercício de linguagem ("poesia não é literatura") com a presença virtualmente performática do corpo e do sujeito que fala para (um) outro(s), mediado por tecnologias audiovisuais hoje de simples acesso. 
Domeneck também faz performances ao vivo em festivais de poesia, mesclando projeção de imagens no fundo do palco, leituras oralizadas de textos escritos e sons mixados, criando uma ambiência performaticamente poética e calcada no conjunto palavra-imagem. Várias dessas aparições estão disponibilizadas em sua página no YouTube e possuem links em seu blog. Coerentemente, Domeneck disponibilizou na internet em 2012 seu primeiro e seu último livro de poemas, Carta aos anfíbios e Cigarros na cama, respectivamente, em solidariedade ao processo sofrido pelo site Livro de Humanas, impetrado pela Associação Brasileira de Direitos Reprográficos (ABDR), por disponibilizar online cópias de livros de editoras brasileiras. Ou seja, o poeta, assim como vários outros poetas e alguns escritores que despontam na literatura brasileira pós-internet, tem uma relação com os direitos autorais diferente das gerações anteriores. O exemplo de Domeneck só politiza o que incontáveis blogs e sites anônimos têm feito militantemente em outra escala com a poesia e que a ex-manager do Grupo Editorial Record, o maior do Brasil, Luciana Villas-Boas, disse certa ocasião sobre quais seriam os primeiros núcleos impressos a migrar para o mercado dos ebooks e textos online: livros de poesia e livros acadêmicos.

Ao lado disso, que podemos chamar de desterritorialização do texto poético (Lévy, 1996: 47), há também uma reterritorialização que parece presente na internet e que se mostra tão interessante quanto de acompanhar. Falamos de uma discursividade lírica tão fartamente encontrada em blogs de sujeitos anônimos e que estereotipadamente - caracterizaríamos por um parágrafo em prosa assemelhado a um híbrido textual, mezzo poético, mezzo prosaico. Geralmente vem acompanhado por uma imagem e descreve algum evento cotidiano em um tom francamente lírico. Até aí, nada de novo, pois desde o século XIX os pequenos poemas em prosa baudelairianos anunciavam a quebra de gêneros como um motivo definidor forte da literatura moderna. Mas essa reterritorialização ocorre depois de que a lírica moderna foi 
praticamente institucionalizada como "fundamentalmente antidiscursiva e autorreferente", sendo isso, no entanto, "muito mais uma lenda ideológica, mais um mito teórico-polêmico do que uma realidade" (Berardinelli, 2007: 177). Historicizando esses híbridos, Alfonso Berardinelli remete aos anos 1960 como a década do esgotamento da ideia de "poesia pura" e da retomada de formas híbridas como o poema ensaístico, a poesia conversada, o poema didático, o panfleto, dentre outros (Berardinelli, 2007: 186). Antônio Risério, numa outra mirada teórica, próxima a de Pierre Lévy, coloca as recentes transformações da materialidade textual em linha de continuidade "semioantropológica" de longuíssimo prazo. Ele toma a linguagem das vanguardas estéticas como signo cultural intermediário entre os grafismos pré-históricos nas cavernas e as experiências holográficas em meios digitais: "de um ponto de vista antropológico geral, não há nenhuma diferença fundamental entre o poeta que aciona a tecnologia do grafite, o poeta que se serve dos tipos móveis de Guthenberg e o poeta que manipula computadores" (Risério, 1998: 53). Foi só recentemente, todavia, com a internet, que se percebeu com muito mais força as formas de reterritorialização textual, o que no Brasil também se evidencia com a grande moda dos microcontos no Twitter e em livros (seria mero acaso Dalton Trevisan, mestre de minicontos, ganhar em 2012 o Prêmio Camões?).

Um poeta que nos parece emblemático dessa reterritorialização é Carlito Azevedo. Laureado desde sua estreia em 1991 com um Prêmio Jabuti, ele já foi capaz de sofisticadíssimos versos como os de "Hotel Inglaterra", com seus intertextos com o suicídio do poeta russo Serguei Iessienin (ocorrido num quarto do Hotel Inglaterra) e com a montagem cinematográfica eisenteiniana (através de uma cuidadosas elipses sintáticas e parentéticas que concentram nos versos referenciais modulados pela plasticidade dos adjetivos):

Brasiliana - Journal for Brazilian Studies. Vol. 3, n.1 (Jul. 2014). ISSN 2245-4373. 
I

Hotel

Inglaterra-

não o negro

pórtico,

a escadaria

dourada

ou a gravidade

da insígnia:

dois leões

empinados

(diz-se

rampantes)

II

se penso

na morte

nem sobre

as lavândulas

à porta

o dulçor da

brisa que

encrespam,

tampouco

o corpo

jacente (e

por terra 


\section{III}

navalha

aberta

e enfim

cumprida,

a grossa

toalha

- já se esvai

a vida -

freando

o repuxo

de sangue

nos pulsos)

\section{(...) (Azevedo, 1993: 16)}

Por outro lado, em seu último livro, Monodrama (2009), depois de quase dez anos sem publicar, Carlito optou por escrever vários poemas em prosa narrativa, recheados em personagens reais ou imaginários, em evidente clave de legibilidade alegórica, como em “Um confeiteiro da cidade de x... observa a foto do asteroide 433 Eros contra um fundo de estrelas num único pixel iluminado":

Nos oito anos em que passou em x... o anjo boxeador experimentou a vertigem e o assombro de uma rotina tão inalterada que certo dia, enquanto pensava na vida média de um nêutron ou nos pés inchados de Édipo, súbito foi atingido pela certeza de que para o dono da confeitaria da esquina, diante de 
cujas vitrines passava pontualmente todos os dias pela manhã, ele não poderia representar nada além de uma estranha forma móvel, acinzentada, que cruzava a rua produzindo na limpidez de suas vitrines uma tênue agitação membranosa, e cuja existência, ou aparição diária, com precisão astronômica, durava nunca mais do que doze segundos. (...) (Azevedo, 2009: 56).

Tal exemplo de Carlito só valida a argumentação deleuziana que Pierre Lévy usa para entender "virtual" não como oposto a "real", sendo virtual na verdade aquilo que potencialmente "tende a atualizar-se", sendo "o nó de tendências ou de forças que acompanha uma situação, um acontecimento, um objeto ou uma entidade qualquer, e que chama um processo de resolução: a atualização" (Lévy, 1996: 15). Atualização por sua vez é "a solução de um problema, uma solução que não estava contida previamente no enunciado. A atualização é criação, invenção de uma forma a partir de uma configuração dinâmica de forças e de finalidades", daí que "o real assemelha-se ao possível; em troca, o atual em nada se assemelha ao virtual: responde-se" (ibidem: 17). A poesia publicada em livro nos últimos anos está na verdade sofrendo uma forte reterritorialização pela migração do campo literário para a internet, tanto no que respeita às negociações entre os diversos atores em cena quanto no que respeita às formas de atualização que na web são possibilizadas enquanto potências virtuais em blogs, redes sociais, ebooks, revistas, sites, diálogo de linguagens artísticas, etc. Assim, do processo que caminhou do livro à internet, percebe-se hoje que - pelo menos no mundo altamente livresco da literatura - uma sutil inversão do fluxo: formas textuais passam da internet para o livro, atualizando a literatura. É o que percebemos no quarto livro de Kátia Borges, formado por pequenos textos em prosa que parecem sintetizar exemplarmente o esforço de comunicabilidade poética em que os autores 
contemporâneos investem na internet, agenciando elementos discursivos variados da tradição, mas que só se tornaram possíveis - hoje - se observamos com cuidado e sem preconceitos o fenômeno tão comum, exemplar e felizmente comunicativo da poesia no mundo virtual. Leiamos "Dedicatória":

É por você, para você, que escrevo. Madrugada alta, imersa em silêncio. No burburinho da redação, ensimesmada. Os dedos curtos teclando. A tela azul recompondo, em alfabeto, o sentido do tempo e do espaço. Para você, volto a fazer poemas. Abandono o álcool e outros vícios. Passo a desacreditar em cartomantes. Por você, entorto todas as linhas traçadas na palma das minhas mãos. Troco meus mapas por desenhos infantis. Fecho os olhos e conto até dez. Por você, prendo a respiração até não mais poder. Respiro fundo e com vigor. Forço a memória. Cito Rimbaud. Falo tatibitate com fluência. Me comporto com decência. Para você, me dispo, sem problemas. Me visto com elegância. Me movimento $\mathrm{cm}$ cuidado. Com a calma que o I Ching indica. Como a raposa atravessando o gelo, sem molhar a cauda. Como Janis Joplin, ao chegar em Port Arthur, depois de mais uma tentativa frustrada de sucesso em San Francisco. Por você, aposento meus CDs de Noel Rosa. Revisito a prosa coloquial das revistas semanais. Aprendo palavras novas em inglês.

Para você, recupero a ousadia de sonhar o meu vocabulário vulgar. Aprendo a aceitar, compreender, perdoar. Me arrisco, me belisco (para acordar). (Borges, 2012: 37-8) 


\section{Resistências}

Diante do até aqui exposto, interessa agora entender o quanto a cultura digital também revitaliza possibilidades que lhe são entendidas à primeira vista como contrárias. Se lançarmos um olhar um pouco mais atento a alguns fenômenos, podemos perceber que sob certos aspectos essas oposições são na verdade falsas, pois pertencem a fenômenos interligados no presente. Depois da música, que sofreu com o baque da distribuição virtual sem intermediários, em uma plataforma como a internet que permite a interconexão com vídeos e outras linguagens, aparentemente chegou a hora da cultura letrada e editorial. Primeiro foram as livrarias que sentiram o impacto das vendas via internet, da sua centralização pelos grandes sites, a exemplo da Amazon. Muitas tradicionais livrarias ao redor do mundo fecharam suas portas irremediavelmente, apesar das campanhas promovidas por clientes fiéis. Com a drástica redução dos estoques das lojas, dadas as facilidades de encomendas, o objeto livro passou a ser um produto com conteúdo cada vez mais especializado nos circuitos livreiros, com um aumento das vendas justamente de livros técnicos, o que sem dúvida é um sintoma das mudanças. Agora - depois das livrarias - chegou a vez das editoras sofrerem com a progressiva digitalização do livro, buscando meios de se adequarem à virtualização do produto, logo também do mercado do livro. Isso tem feito com que o livro se descole paulatinamente da educação formal - que até hoje o usou como importantíssimo instrumento pedagógico -, ganhando ares de produto eminentemente comercial. As próprias pesquisas e propostas no sentido de incluir no cotidiano da sala de aula ferramentas digitais e plataformas virtuais só reforça esse cenário de decadência relativo ao livro. Sua promoção comercial e virtualização modernosa pelos ebooks se faz plasmada à virtualização da economia financeira em mercado global de capitais: 
editoras negociam ou se fundem em grandes conglomerados transnacionais (veja-se os recentes casos da venda de $45 \%$ da brasileira Companhia das Letras à inglesa Penguin Books ou a expansão da espanhola Alfaguara) e sites de livrarias também se expandindo (a ansiosamente aguardada - por leitores - e negociada - por editoras - entrada da livraria virtual Amazon no mercado brasileiro é exemplo eloquente).

Nota-se que no campo literário se reduziu de modo expressivo a relação de proximidade, e mesmo cumplicidade, que existia entre editor e autor (o maior exemplo brasileiro foi a relação que o editor José Olympio estabeleceu com um grande grupo de modernistas, de Carlos Drummond de Andrade e Jorge Amado a João Cabral e Guimarães Rosa), hoje transformada em uma pragmática relação comercial. O editor agora pode ser visto na grande maioria dos casos como um businessman que - como o livreiro - age para fazer o produto (cada vez mais virtualizado) chegar ao leitor, ser rapidamente consumido e substituído pelo próximo. Isso tem feito com que o tradicional autor se veja condicionado por interesses fundamentalmente financeiros, e suas ideias, sua independência e esforço criador e crítico se vejam dia a dia mais submetidos à lógica financeira do mercado. É o que os diretores de marketing e financeiros chamam de economia criativa. No cenário que se desenha contemporaneamente, vemos de modo progressivo os interesses políticos, sociais e culturais submetendo-se - quando não se confundindo - a interesses financeiros de grandes conglomerados econômicos e grupos políticos, em que o valor de um dado discurso artístico depende às vezes mais do investimento na sua cosmética do que na sua criação medular. Esse cenário faz com que aqueles que vêm o conteúdo do livro mais do que simplesmente um bem de troca mercantil busquem ao mesmo tempo formas de resistir à radical capitalização e mercantilização da leitura e da literatura.

Com o produto livro descolando-se do campo educacional, a relação afetiva e prazerosa com o objeto livro (e com a leitura) pode (re)aparecer como forma de 
resistência às formas de sedução e controle comercial. Uma estratégia dessas formas de resistência afetiva à mercantilização da leitura é o movimento, um tanto estereotipado, do slow reading, que busca se contrapor à lógica produtivista da leitura veloz e funcional e recuperar para o gesto da leitura um espaço que mescla prazer e entretenimento sem função apenas informativa. Outra estratégia, esta mais comprometida, é a recusa em tratar a literatura e o livro como produtos inevitavelmente comerciais. Vários autores têm reassumido o papel dos antigos trovadores e segréis medievais, assim como também o dos cordelistas nordestinos, no sentido de reunir em um só indivíduo as funções de escritor, editor, divulgador e vendedor da sua arte. Seja com a confecção digital do próprio ebook, sua divulgação e venda através dos blogs e das redes sociais na internet, seja com a autopublicação, hoje muito mais barata do que há vinte anos. Com isso, faz-se a ponte entre o escritor pós-internet e o artesão pré-moderno e retorna a figura o Autor-Editor, ou mesmo - mais radicalmente - do Autor-Impressor, como nos primórdios da era moderna, conforme anota Peter Burke em seu livro Uma história social do conhecimento: de Guthenberg a Diderot. Nele, Burke, a certa altura, afirma que "uma das principais consequências da invenção da prensa tipográfica foi ampliar as oportunidades de carreira aberta aos letrados. Alguns deles se tornaram letradosimpressores" (Burke, 2002: 28). Um exemplo atualíssimo é o crescente fenômeno latinoamericano das Cartonerias, coletivos de escritores, artistas plásticos e cooperativas de recicladores de papel que usam suas respectivas especialidades para criar belíssimos Livros de Artista, com texto e desenhos exclusivos e que são obras de arte originais, não reprodutíveis, de intervenção social e marginais ao grande circuito comercial. No Brasil, o mais ativo e famoso coletivo é o Dulcinéia Catadora (2012).

Uma outra experiência e que chama a atenção - em certo sentido antecipatória desse artesanato resistente e anti-comercial do livro - foram as Edições Civilização Arcaica Brasileira. Um projeto conjunto de Alex Cojorian e Cintia Falkenbach, a criação 
artesanal de livros teve pequena repercussão, mas um grande êxito em anunciar - entre 1994 e 1999 - o atual cenário das Cartonerias. De dentro da Gráfica Experimental e do Ateliê Livre de Gravuras do Instituto de Artes da Universidade de Brasília - e munidos menos com tino comercial e mais com senso criador coletivo -, os editores conceberam esse projeto com o intuito de revalorizar o livro como objeto singular - mas não necessariamente um objeto de luxo. Feito com qualidade artística e cuidado artesanal, buscavam recuperar, segundo o folheto da exposição de lançamento,

a vocação pela arqueologia da memória, o esforço de erguer e de reerguer o castelo primordial da gravura. Verba volant, scripta manent: gravada na pedra rústica, impressa no álbum encadernado - distância longa no tempo, breve no espaço, sempre a representação arcana e mítica da Rocha Primitiva, do Sol, do Calango, da Palmeira, da Sexualidade, do Feito Épico. Eis a força do passado, a força da memória e do múltiplo: letra e imagem impressa e reproduzida (Cojorian, 2012)

Na sua experiência antecipatória do atual retorno dos livros de artista, as Edições Civilização Arcaica Brasileira editaram em pequenas tiragens libretos em diversos formatos, em prosa e verso, com imagens originais de gravuristas convidados, numerados e assinados pelos artistas. Uma amostra das impressões vai do conto Lua da vaidade, de Alex Cojorian, com linoleogravuras de Cintia Falkenbach, em 49 exemplares, passando pelas As 7 Regras de Vida. Preceitos para a saúde física e mental, de Paracelso, de tradução anônima, com xilogravura de Sylvio Xilo, em 200 exemplares, A Fênix: o mito solar da ave Benu, de Antonio Cavalcanti, com clichê de Cintia Falkenbach e linoleogravura de Alex Cojorian, em 135 exemplares e o Múltiplos Eróticos: Gravuras e 
Trovas, com 22 participantes, entre gravadores e trovadores, de diversas gerações, como Rogério Duarte, Marília Rodrigues, Astrid Cabral, Maciej Babinsky, Pulika, visitando o tema do erotismo, em 100 exemplares.

Sobre este último álbum - um bonito exemplar desse projeto de artesanato bibliográfico e sem nenhuma queda pela economia do luxo na sua concepção - a relação entre erotismo e criação se estabelece como eixo principal. As tentativas humanas de domar a força animal através de gravuras nas paredes das cavernas é uma produtiva alegoria da relação que Múltiplos Eróticos estabelece entre sua forma artesanal e o sentimento erótico. A encadernação do livro em papel reciclado, em forma de álbum abrangendo folhas soltas preparadas para a costura pelo leitor, e as combinações de xilogravuras coladas com pequenos versos e clichês impressos parecem reviver os fetiches do prazer erótico. Sem qualquer intenção reprodutivo-comercial, o erotismo de Múltiplos Eróticos está tanto no manuseio físico do álbum quanto em trovas de matrizes flagrantemente populares como: "Lagarto, larga a pedra dura / E o sol do meio-dia, / Vem refugiar-se nesta gruta, / Úmida, escura e nada fria”, de Alex Cojorian, ou “O triângulo das bermudas / não é o triângulo mineiro / mas todo triângulo amoroso / é um círculo vicioso", de Astrid Cabral, ou ainda "Se em sonhos eróticos / Volverdes os olhos para os céus / E verdes um cu / Meta!", de Luiz Antonio. O prazer do livro e o livro do prazer sobrepõem-se em uma experiência de leitura que não reduz o valor artístico a um valor comercial, nem reduz a ideia de sociedade a uma de mercado. Daí, o se entrevê nas Edições Civilização Arcaica Brasileira e em uma lógica baseada no valor do artesanal é a sua opção cultural pelo arcaico, pelo rústico, pelo ruído, pelo local e pelo anti-comercial, em tempos que o valor imaterial do dinheiro domina e esteriliza a totalidade da nossa vida subjetiva e objetiva. Livros caseiros e artesanais são formas de resistência criativa que podem e devem retornar nesses tempos também de controle digital crescente.

Brasiliana - Journal for Brazilian Studies. Vol. 3, n.1 (Jul. 2014). ISSN 2245-4373. 
Se, como afirmou Luciana Vilas-Boas, anteriormente citada, os livros acadêmicos e de poesia seriam os primeiros a migrar para formato digital, isso faz todo o sentido pelo ponto de vista do circuito comercial; mas, enquanto produto artístico, os livros de poesia parecem ter vida longa a desenvolver no âmbito dos Livro de Artista. Exemplar disso é o recente O LIVRO de água (2013), feito a quatro mãos por uma poeta (Karina Rabinovitz) e uma artista visual (Silvana Rezende). Articulado a uma exposição multimídia no Museu de Arte Moderna da Bahia e a performances, que incluíam de simples leituras públicas de poemas até projeção de slides e vídeo-poemas - o livro traz 96 cartões ilustrados e numerados com fotos manipuladas que incluem breves poemas escritos à mão sobre suportes que vão de cadernos variados a paredes e muros, vários deles presentes na exposição; há também fotos recortadas dos vídeo-poemas presentes à exposição. Tudo vem enformado numa caixa de plástico transparente com o título e os nomes das autoras em alto relevo.

Como Ricardo Domeneck, alguns afirmam que a poesia nunca pertenceu necessariamente à arte literária, mas que estaria muito mais próxima da música ou das artes plásticas. É essa afirmativa que Karina e Silvana parecem endossar, sem querer ao mesmo tempo desvincular-se da tradição moderna, pois ali também estão versos escritos por Karina em um produto chamado "livro". Além da união de imagem e poesia, os cartões manuseados plasticamente parecem formar uma sequência melódica de imagens e palavras, trazendo a música para o livro, uma música muito mais presente no gesto de ler-e-manipular os cartões. T.S. Eliot dizia que a música na poesia moderna definir-se-ia por um "ritmo particular" que "pode levar ao nascimento da ideia ou da imagem" (Eliot, 1991: 55) e suas posteriores reiterações, derivas e diálogos. Karina e Silvana parecem dizer que sua música estaria na manipulação por parte do leitor das imagens fotográficas com seus versos propostos, num complexo campo artístico 
expandido. O que importa, nesse Livro de Artista, é o seu discurso total, os conceitos criados no projeto das duas autoras. E isso é poesia e resistência.

Todas essas rearticulações no campo literário - causando enormes e incômodas flutuações naquilo que paradoxalmente sempre foi por definição indeterminado como a poética moderna - são classificadas pela crítica argentina Josefina Ludmer como o campo das "literaturas pós-autônomas". Isto é, quando "todo o cultural (e literário) é econômico e todo o econômico é cultural (e literário)" (Ludmer, 2010: 02), deslocando as tradicionais esferas do pensamento de campos considerados autônomos uns com relação aos outros (quando arte, política e moral não se misturariam nos julgamentos de valor estético em um Estado laico e em que religiosidade seria questão de foro privado). A ideia de uma autonomia dos campos pertence ao pensamento emancipador do iluminismo. Já a perspectiva pós-autonomia fabrica, segundo Ludmer, “o presente com a realidade cotidiana $[\ldots]$, realidade cotidiana do presente de alguns sujeitos em uma ilha urbana (território local). Formariam parte da fábrica do presente que é a imaginação pública" (ibidem: 02-3). A presença desse presente nos leva de volta ao projeto pedagógico das Humanidades de Gumbrecht, que abre nosso texto e que não recorre à noção tradicional de crítica, pelo contrário: “aceito que o que digo neste livro não está de acordo com a expectativa geral de que o nosso trabalho nas Humanidades será 'crítico' num sentido político ou (menos especificamente) num sentido 'social'" (Gumbrecht, 2010: 175), mas recorre a um sentido de resistência diante de uma canibalesca hipercomplexidade do mundo - resistência pela presença dos nossos territórios locais, com uma outra política e uma outra cultura letrada, com as feiras e festas literárias, os escritores transformados em fugazes celebridades, as performáticas estratégias de autodivulgação, as amizades literárias, etc. Tudo isso tem sua faceta de arte da resistência, mas também de arte do cinismo. 


\section{Referências Bibliográficas}

Azevedo, Carlito. As banhistas. Rio de Janeiro, Imago, 1993.

. Monodrama. Rio de Janeiro, 7 Letras, 2009.

Berardinelli, Alfonso. Poesia e gênero lírico: vicissitudes pós-modernas. Da poesia à prosa. Trad. Maurício Santana Dias, São Paulo, Cosac Naify, 2007.

Borges, Kátia. O escorpião amarelo. Salvador, P55, 2012.

Bourdieu, Pierre. Les règles de l'art. Paris, Éditions de Seuil, 1992.

Burke, Peter. Uma história social do conhecimento: de Guthenberg a Diderot. Trad. Plínio Dentzien, Rio de Janeiro, Jorge Zahar Editor, 2002.

Cojorian, Alex, Falkenbach, Cinthia et ali. Múltiplos eróticos: gravuras e trovas. Brasília, Edições Civilização Arcaica Brasileira, 1996.

Deleuze, Gilles, Guattari, Félix. Mil platôs, vol. 1. Trad. Ana Lucia Oliveira, Rio de Janeiro, Ed. 34, 1995.

Domeneck, Ricardo. A cadela sem Logos. São Paulo, Cosac Naify/ Rio de Janeiro, 7 Letras, 2007.

Eliot, T. S. A música da poesia. De poesia e poetas. Trad. Ivan Junqueira. São Paulo, Brasiliense, 1991. 
Gumbrecht, Hans Ulrich. Produção de presença. O que o sentido não consegue transmitir. Trad. Ana Isabel Soares, Rio de Janeiro, Contraponto/PUC-Rio, 2010.

Lévy, Pierre. O que é o virtual? Trad. Paulo Neves, São Paulo, Ed. 34, 1996.

Passetti, Edson. Anarquismos e sociedade de controle. São Paulo, Cortez, 2003.

Rabinovitz, Karina, Rezende, Silvana. O LIVRO de água. Salvador, P55, 2013.

Risério, Antônio. Ensaio sobre o texto poético em contexto digital. Salvador, Fundação Casa de Jorge Amado, 1998.

\section{Web-sites}

Cojorian, Alex. "As Edições Civilizações Arcaica Brasileira". Revista Verbo21. Agosto de 2008.

$<$ http://www.verbo21.com.br/v1/index.php?option=com_content\&view=article\&id=141 \%3Aas-edies-civilizao-arcaica-brasileira-alex-cojorian\&catid=108\%3Aresenhas-eensaios-agosto2008\&Itemid=107> (último acesso em 20/08/2012).

Domeneck, Ricardo. Rocirda Demencock. <http://ricardo-domeneck.blogspot.com.br> (último acesso em 18/08/2012).

Garganta com texto. 2006.

$<$ http://www.youtube.com/watch? $\mathrm{v}=\mathrm{sZ}$ wFos5meBU\&feature=plcp $\geq$ (último acesso em 18/08/2012).

Dulcinéia Catadora. <http://www.dulcineiacatadora.com.br/noticias_news_1.html $\geq$ (último acesso em 07/12/2012). 
Ludmer, Josefina. "Literaturas pós-autônomas", Sopro. Panfleto político-cultural. Trad. Flávia Cera, Desterro, Cultura e Barbárie, n. 20, jan, 2010, 01-4. $<$ http://www.culturaebarbarie.org/sopro/n20.html (último acesso em 28/05/2013)

Rabinovitz, Karina. [Coleção de] Sussurros. <http://karinarabinovitz.blogspot.com.br> (último acesso em 27/05/2013)

Rezende, Silvana. VietKingKong. <http://silvanarezende.wordpress.com> (último acesso em 27/05/2013) 